\title{
Improved Processing Research on Arc Tooth Cylindrical Gear
}

\author{
Zhang Zheng ${ }^{1}$, Tang Rui ${ }^{2, *}$ \\ ${ }^{1}$ School of Mechanical Engineering, Xihua University, Chengdu, China \\ ${ }^{2}$ School of Mechanical Engineering, Panzhihua University, Panzhihua, China
}

Email address:

pzhutr@163.com (Tang Rui)

${ }^{*}$ Corresponding author

To cite this article:

Tang Rui, Zhang Zheng. Improved Processing Research on Arc Tooth Cylindrical Gear. International Journal of Environmental Monitoring and Analysis. Vol. 5, No. 3, 2017, pp. 91-95. doi: 10.11648/j.ijema.20170503.14

Received: February 24, 2017; Accepted: March 23, 2017; Published: June 29, 2017

\begin{abstract}
Based on the analysis of arc tooth cylindrical gear forming principle and on the basis of existing processing methods, also combined with the principle of ordinary milling knife plate rotating, This paper puts forward an improved double-edged milling method of the Arc tooth cylindrical gear, which include two aspects: one is the double edged sword substance milling gear, double-point tool forming tooth at a time, with the module gear form point contact transmission vice; The second is to use double tooth gear milling tool, cutting tool a tooth, the gear machining and broadsword dish of double edge milling gear transmission line contact vice. It concluded that the improved processing technology is more advanced, the method of production is more efficient.
\end{abstract}

Keywords: Arc Tooth Cylindrical Gear, Double-Edged Milling, Processing Method

\section{Introduction}

A mechanical components to a great extent, decides the performance of machinery and equipment, the development of manufacturing. Gear transmission is the most widely used in all kinds of mechanical equipment transmission form, also it is the the basis of the very important parts. Gear meshing characteristics of the direct impact on the performance of machinery and equipment, research and development of high performance of the meshing pair is an eternal subject for the development of academic research and the gear industry [1]. Line circular arc tooth cylindrical gears as a new type of gear, the meshing performance is good, the contact line length, large contact ratio, no axial force component, has a large carrying capacity, high transmission efficiency, smooth transmission and other characteristics, it instead of the ordinary cylindrical gears use, has good application prospect [2-3].

\section{Circular-Arc-Tooth-Trace Cylindrical Gear Forming Principle}

Arc cylindrical gear tooth line compared with ordinary cylindrical gear, the tooth line is more special, along a bus bar in the plane assumes the circular cylinder. With the same modulus, tooth number, tooth width of straight gears, helical gears, herringbone gear with circular arc tooth cylindrical gears began along the cylinder gear, spur gear and helical gear tooth line respectively in a straight line with inclined straight lines, and herringbone gear with circular arc gear tooth line of line and arc respectively. Arc cylindrical gear tooth line, therefore, both have the characteristics of herringbone gear contact line length, and avoid the herringbone gear processing needed relief groove, carrying capacity is strong, good structure process.

Equivalent basic rack is the basis of the geometric parameters of gear tooth and gear cutting tools, milling knife plate rotating arc cylindrical gear tooth line equivalent of the basic rack as shown in figure 1. Proposed in this paper improve the method of double edge milling knife plate rotating on the machining principle is similar to ordinary single blade machining and two edges, and gain the basic single blade machining and double rack have certain differences. Single blade processing of convex and concave tooth surface of gear teeth is two cone apex Angle and equal position instead of cone surface part of the $\mathrm{M}$ and $\mathrm{N}$, as shown 
in figure 1 (a). The two cone axis parallel to the spacing for half of the pitch, that is. If take cone top half Angle, processing of the rack is basic arc-gear wire rack, its equivalent rack for processing cutting tool, features two points A-A plane on the axis of the cone in the middle of the tooth width direction, the plane is in cross section. Rack and dividing plane B-B and the conical surface of $\mathrm{M}$ and $\mathrm{N}$ for the intersecting line of two section of the radius of circular arc, as shown in figure 1 (B). Adopt double-point tool processing the basic rack as shown in figure 1 (c), rack and dividing plane B-B and the intersection of a cone surface $\mathrm{M}$ and $\mathrm{N}$ are the two radius of circular arc, the center line of the tooth socket name of cutter radius. These two forms of equivalent basic rack, rack for arc-gear line and its conjugate gear is circular arc tooth cylindrical gears. The rack also has the following features [4].

(1) The equivalent basic rack in section A-A slit, the cross section of tooth profile of straight tooth shape, tooth profile Angle are on both sides, and the edge where the cone cone top half Angle is equal, therefore, in the cross section of tooth profile and involute gear tooth profile of basic rack.

(2) In the cross section and end face between the parallel section, tooth shape each are not identical, and both sides of the same cross section tooth profile is different.

(3) Along the dividing plane of B-B cut open, single blade cutting tool machining gear's tooth line radius on both sides of the same, its value is, and the normal tooth thickness and the tooth groove width is equal.

(4) Along the dividing plane B-B cut open, double edge machining gear's tooth line on both sides of the radius is different, tooth concave tooth line radius is greater than, the tooth convex tooth line radius is less than.

(5) On the dividing parallel to the plane of the cross section, concave, convex tooth line is the radius of circular arc. In convex tooth surface, and its radius from the tip to the tooth root increases gradually, the concave tooth face its change law instead. In root position, single blade processing tooth convex radius are greater than concave tooth line. Parallel section near the end, the greater the tooth profile of gear tooth thickness, as shown in figure 1 (a). Therefore, this kind of tooth root of pinion and rack was strengthened. On the top of the tooth, as shown in figure $1(\mathrm{~b})$, the changing rule of the tooth shape and tooth root instead; Double machining gear's tooth shape change rule and the single blade tooth is similar, but the radius of concave and convex surface tooth line in dividing plane, radius of concave tooth line generally is greater than the radius of convex tooth line, as shown in figure 1 (c).

(6) As shown in figure 1 (a) processing method of basic rack can be the same as the $180^{\circ}$ was reversed rack joint; As shown in figure 1 (c) machining method of the basic rack can be the same as the $180^{\circ}$ was reversed rack form point contact. Basic rack of concave and convex tooth surface as shown in figure 1 (d).

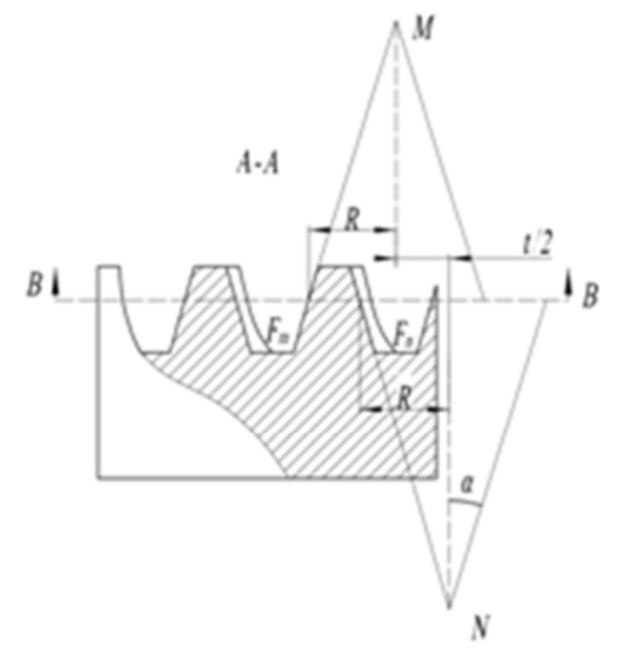

(a) Single blade processing rack in the middle section

$B \cdot B$

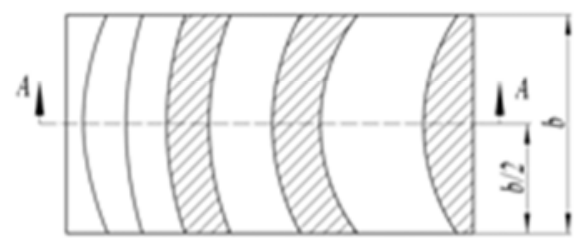

(b) Single blade processing rack dividing plane

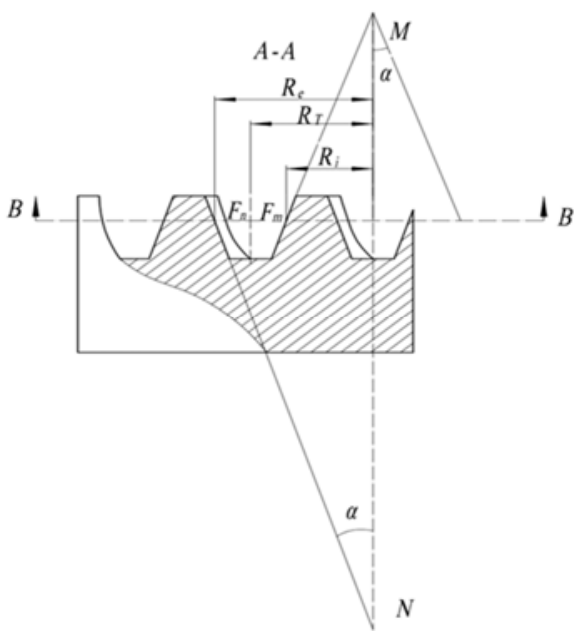

(c) Double edge processing rack in the middle section

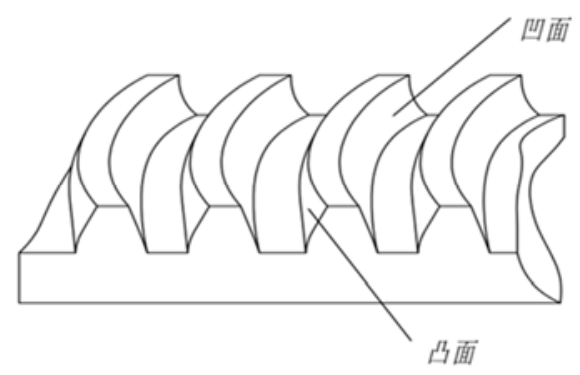

(d) Single edge or double edge processing rack 


\section{Common Method Arc Tooth Cylindrical Gear Processing Line}

At present various literature presented a variety of processing methods of line arc tooth cylindrical gear, such as: sword plate of indexing teeth, and the diameter of the downside is the knife dish, request knife rotating speed is low, the applicable scope of the radius of the tooth line is relatively small; Nc hobbing machining while efficiency is high, but the cutter blade and finished after tooth surface easy to generate interference, radius of the smaller gear processing is difficult; Three rotating cutting method of the cutting tools need three time processing, and many times the knife, the operation is inconvenient, influencing machining accuracy; Translation method processing of arc tooth cylindrical gear line requires translation tool, cutting tool center plane method to constant, the gear processing and shaping of axial displacement error and Angle error and center distance, load distribution inhomogeneity is serious; Rotary cutter milling method, this kind of gear form the drum gear, is not sensitive to installation error, can form the dynamic pressure of oil film, has the good lubrication performance, and this kind of gear cutting with high efficiency machining method, to reform the existing machine tools or design special machine tool is easy to implement this kind of gear machining [5-8].

Ordinary milling knife plate rotating arc tooth cylindrical gear line have more advantages than other processing method, using universal milling machine, hobbing machine and gear grinding machine bed etc. Processing can be realized. By processing the arc cylindrical gear tooth line can achieve high hardness after quenching, grinding and precision [9].

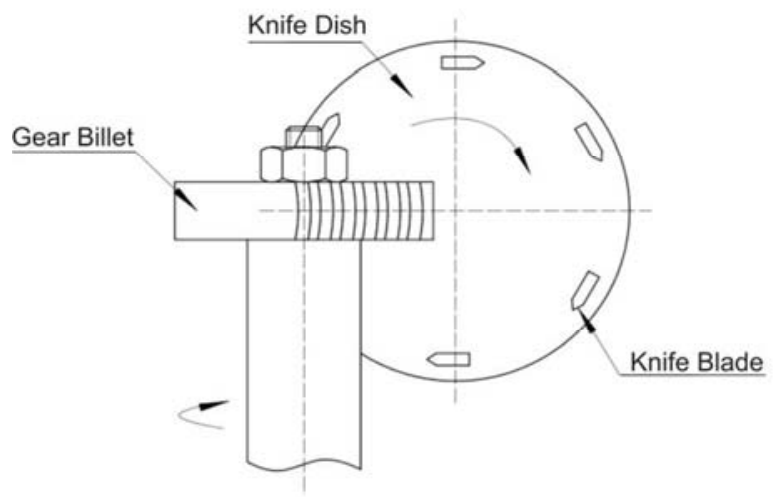

Figure 2. Rotating cutter blade show line into a circular arc tooth cylindrical gears.

Gear milling machine processing, installed on the main shaft of the cutter and cutting the workpiece formed into motion, as shown in figure 2 . In the process of gear cutting, single blade can cut out a tooth profile, and the double blade can cut out a tooth, namely cut into concave and convex tooth surface at the same time. When the blade after cutting a tooth, tooth single-tooth indexing, gnash the teeth in the position of the blade on the next tooth, so repeatedly dividing and teeth, gradually complete tooth processing. Processing in the process of exercise is as follows:

(1) The knife wound its axis of rotation, namely the main movement;

(2) The knife dish along the gear pitch circle tangential movement and artifacts around its own axis rotation, namely of selecting such assignment movement;

(3) The knife dish of the feed, the blade and dividing movement. In milling knife plate rotating arc cylindrical gear tooth line, can use single edge or double edge tool for processing.

Used as shown in figure 3 (a) double-point tool processing arc gear tooth cylindrical gear line, can also cut out a tooth of the gear processed, inner and outer edges are concentric circles. Because concave and convex tooth surface forming radius is different, so different depth location section assumes the crescent, as shown in figure 3 (b), its shortcoming in the cross section of small bending modulus, tooth root bending strength weakened somewhat. But this kind of tooth shape for the drum gear, meshing pair of contact region is sensitive to errors of manufacture, installation, etc. Processing in addition to this, this method was easy to form oil wedge, when the tooth meshing can form stable dynamic pressure oil film, the friction loss is reduced, agglutination resistance increase [10]. In addition, this kind of machining method of gear can cut out a tooth at a time, processing efficiency is relatively high.

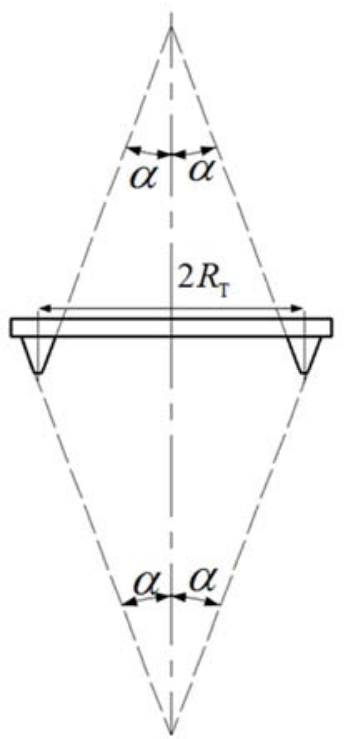

(a) Double edge.

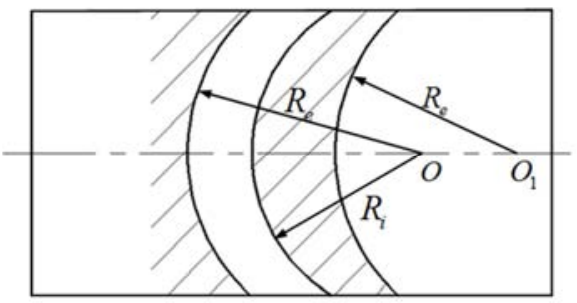

(b) Double edge processing gear tooth profile.

Figure 3. Double edge milling knife plate rotating arc tooth cylindrical gear. 


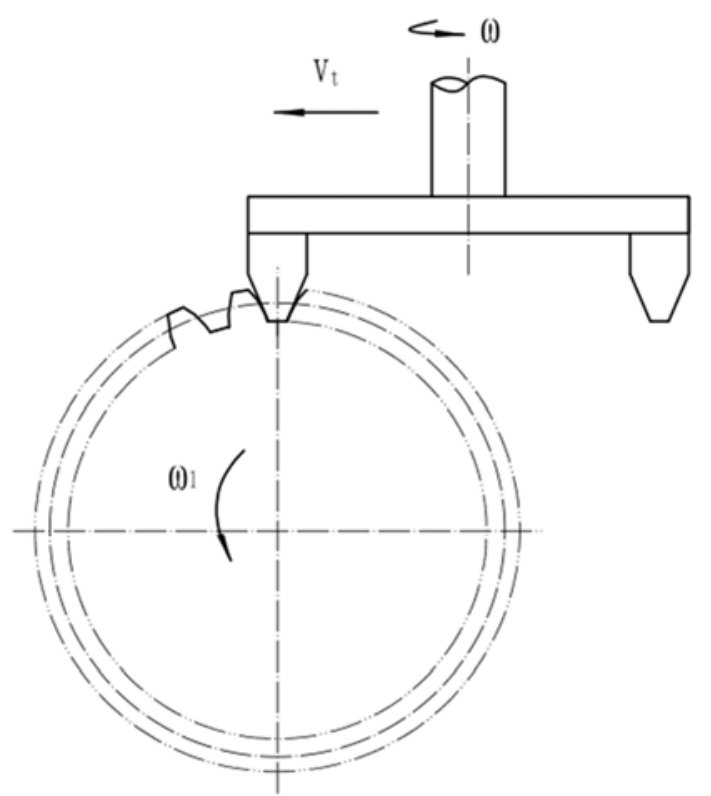

(a) sword plate of double edge milling

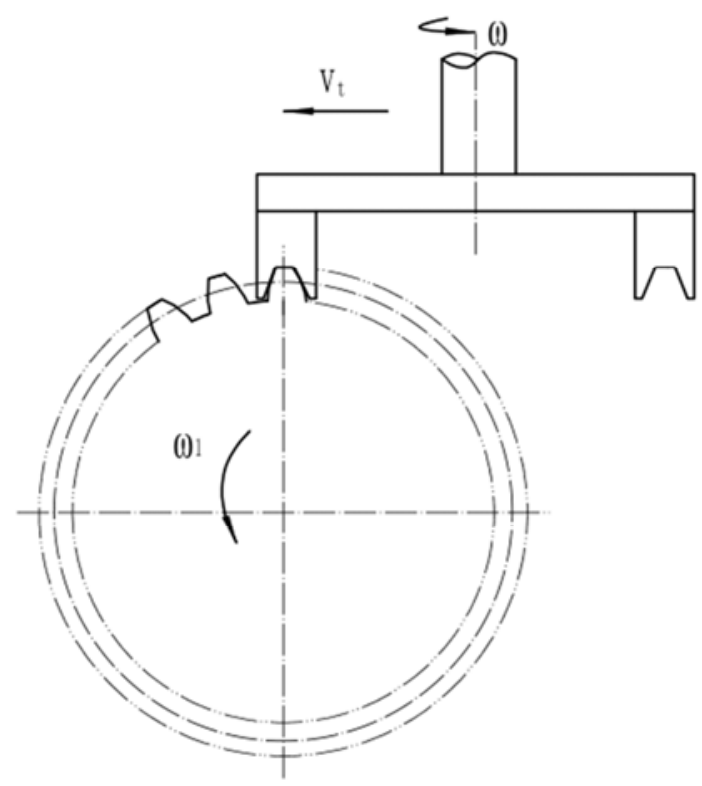

(b) double-point tooth cutting tool machining

Figure 4. Improved double milling arc tooth cylindrical gear.

\section{An Improved Double Edge Milling Method}

In order to obtain good performance contact gear before, often two processing arc tooth cylindrical gears. Adopts double blade for rough machining, again with radius equal precision work inside and outside single blade cutting tool, the convex and concave tooth surface of cutting tooth, respectively, can get high precision gear. But it has increased the complexity of the process, making ordinary rotating cutter milling processing method for manufacturing the gear is not widely used. Based on the ordinary milling knife plate rotating method and its principle as the foundation, improve the method of double edge milling is put forward. Include two aspects: first, the double edged sword substance milling gear, double-point tool forming tooth at a time, with the module gear form point contact transmission vice; Second, the use of double tooth gear milling tool, cutting tool a tooth, the gear machining and broadsword dish of double edge milling gear transmission line contact pair. Improve the method of double edge milling is the improvement of common processing method of cutter and gear transmission vice build method improvement. Through the analysis of various factors influencing the performances of gear pair meshing, demonstrates the feasibility of the gears are processed using the two-edged tool at a time, in order to gain the machining method and technology of the production efficiency is higher. On the one hand, by increasing the cutter radius point contact mesh to improve performance, by studying the parameters matching relation between improvement tool, so as to improve the gear meshing performance, improve the transmission capacity, in order to distinguish from general tool processing, the paper says the sword plate of double edge milling or double edge milling, double blade tooth cutting tool, as shown in figure 4 (a). On the other hand, according to the concept of gear pairs using the double gear tooth cutting tool processing, as shown in figure 4 (b), and the sword plate cutting tool machining of gear pairs with double gear. Adopt double gear cutting tools, forming a tooth indexing can be a; Using tooth cutting tools, dividing can be forming a tooth at a time. This method can be used for matching gear to achieve line contact, machining efficiency and machining precision can be guaranteed. Alveolar cutter two edges constitute the basic rack of a tooth, and two edges rotating axis parallel to the axis of symmetry and the knife, two axis distance denture line for the name of the cutting tool radius, this principle called two-edged tooth cutting tool machining method. Without considering the installation error, formed by two methods of processing gear may constitute a point contact and line contact transmission vice, this paper combines the use of these two kinds of methods, called double milling method improvement.

Sword plate of double-edged milling

From the point of a blade forming principle, processing method for improving the machining principle and common method principle is similar, but double tooth cutting tool processing the tooth surface concave and convex type and common method is the opposite. Tooth cutter blade machining is convex tooth surface, in outer edge processing is concave tooth surface; Alveolar cutter blade machining is concave tooth surface, in outer edge processing is convex tooth surface. If the sword plate of double edge milling cutter in machining method of internal and external blade in dividing cutter radius, respectively, in the name of the plane, the double spline tool processing method of internal and external in dividing plane blade cutter radius, respectively, in the name of the, tooth surface, the corresponding forming. Because two cutter head radius of the same name, Therefore, by two cutter cutting two gears, matching use can ensure the line contact, transmission can be realized. 


\section{Acknowledgement}

In the existing circular cylindrical gear tooth line processing method based on the proposed improved double edge milling machining method for manufacturing. Which include sword plate of double edge milling and double tooth cutting tool processing, this method combines ordinary milling knife plate rotating with matching an advantage of using the concept, the gear machining can be build in the form of two kinds of contact transmission vice, solve the multiple contradictions in the design, manufacture, application and provides a simple design, easy fabrication, high bearing capacity of circular arc tooth cylindrical gears design methods, this method can realize gear grinding technology, machine tool design and modification easy, high processing efficiency, stable precision, this kind of gear and its processing method has a good industrial application prospect.

This work is supported by grant 51375320 of the Chinese national natural science fund.

\section{References}

[1] Hai-xiang li. Basic theory of gear transmission and the growing surface test research [D]. Chongqing university, 2012.

[2] Xiao-wei sun. The characteristics and processing method of arc tooth gear [J]. Journal of mechanical engineer, (8):1999-22.
[3] Yang Zhi. Small module the study of the theory of the spiral bevel gear nc gear cutting processing [D]. Suzhou: suzhou university, 2004.

[4] Guo Haisheng. A new type of cylindrical gear teeth method research [J]. Journal of shanxi coal, 1997, (2):27 to 30, and technology press, 1991

[5] Zou Min. Arc cylindrical gear tooth line parameter calculation and selection $[\mathrm{J}]$. Journal of mechanical design and research, $2000,2: 36$ to 38 .

[6] Yutang dai, there have been He Xing, de-sheng jiang. Arc cylindrical gear tooth line nc hobbing mechanism and experimental study $[\mathrm{J}]$. Journal of mechanical engineering, 2006, 17 (7):706-709.

[7] KouShiYao Liu Mingbao, liang-chen wu. A new method of arc tooth cylindrical gears processing $[\mathrm{J}]$. Modern manufacturing engineering, 2002 (9):16-17.

[8] Ai-ping song, wei-wei wu, noble, Gao Wenjie. Arc tooth cylindrical gears ideal geometric parameters and their processing methods [J]. Journal of Shanghai jiaotong university, 2010. 44 (12):1735-1740.

[9] $\mathrm{Wu}$ Daren LuoGuShun. Gear engagement principle [M]. Beijing: the new era of publishing house, 1983.

[10] R. T. Tseng, C. B. Tsay. Mathematical model and undercutting of cylindrical gears with curvilinear shaped teeth [J]. Mechanism and Machine Theory, 2001, 36:1189-1202. 